\title{
A Review on Diagnosis and Management of Diabetes Mellitus in Dogs
}

\author{
Shabnam Sidhu* and Swaran Singh Randhawa \\ Department of Veterinary Medicine, Guru Angad Dev Veterinary and Animal Sciences \\ University, Ludhiana, India \\ *Corresponding author
}

\section{A B S T R A C T}

\section{Keywords}

Diabetes mellitus,

Dogs, Pancreas,

Fructosamine,

Glycated

hemoglobin

Article Info

Accepted:

04 May 2019

Available Online:

10 June 2019
Diabetes mellitus (DM) is one of the most common endocrinopathies observed in dogs. The main clinical manifestations are polydipsia, polyuria, polyphagia, weight loss and glucosuria. The etiology of diabetes mellitus is similar in dogs, cats and humans and is probably multifactorial (genetic, immune and environmental factors). Diabetes mellitus is described to be deficiency or absolute lack of insulin secretion is divided into two types: insulin dependent diabetes mellitus (IDDM) and non-insulin dependent diabetes mellitus (NIDDM). Various breed susceptibilities have been reported. Conventionally diagnosis of canine DM was based on persistent fasting hyperglycemia and glucosuria. However, nowadays serum fructosamine, glycated hemoglobin $(\mathrm{GHb})$ and glycated albumin (GA) measurements are used to complement blood glucose concentration for the diagnosis and treatment response monitoring of DM. Traditionally, management of DM is achieved by insulin administration, diet, regular exercise and oral hypoglycemic drugs. Alternate therapies like use of encapsulated islet, gene therapy etc. are being evaluated for its clinical application in the efficient management of DM. This review will briefly summarize our current knowledge about the diagnosis and management of diabetes in dogs.

\section{Introduction}

Diabetes mellitus is one of the most common endocrinopathies observed in middle to old aged dogs, characterized mainly by hyperglycemia, glycosuria and weight loss, resulting from absolute or relative deficiency of insulin (Audrey, 2012). Pathologically, it is a multiple organ affecting disorder in which the body has chronic carbohydrate, protein and fat metabolism failure, specifically in the insulin responsive organs. The etiology of diabetes mellitus development is similar in dogs, cats and humans (Nelson and Reusch, 2014). The etiology of diabetes mellitus in dogs is probably multifactorial. Factors contributing to the development of diabetes mellitus are genetic, immune and environmental factors.

Genetic factors influence susceptibility, specific genes and inheritance patterns. Environmental factors playing role could be obesity, diet, exposure toxicants or drugs. Immune-mediated destruction of islet cells and destruction of islet cells secondary to 
pancreatitis may play a role in establishing pathogenesis (Guptill et al., 2003).

Pathophysiologically, diabetes mellitus is described to be deficiency or absolute lack of insulin secretion by the beta cells of the pancreas or decreased number of insulin receptors (Wubie and Getaneh, 2015).

On the basis of degree of beta-cell insulin production failure, diabetes mellitus is divided into two types: insulin dependent diabetes mellitus (IDDM) and non-insulin dependent diabetes mellitus (NIDDM). Type 1 diabetes (IDDM) is more common in dogs as compared to type 2 diabetes mellitus (Feldman and Stephen, 2005).

Understanding on susceptibility of dogs to diabetes as an effect of breed, age and sex has been reported by many researchers worldwide. Breeds like Poodles, Keeshounds, Alaskan Malamutes, Miniature Schnauzers, Cairn Terrier and English Springer Spaniels are reported to be under high risk for spontaneous development of diabetes mellitus, However, German Shepherd, Cocker Spaniels, Collies and Boxers breeds are considered to be in the low risk group (Guptillet al., 2003; Catchpole et al., 2013). Almost all breeds of dogs are susceptible, however mixed and large breed dogs are more susceptible to the disease (Feldman and Nelson, 2004).

Although DM is a non-curable disease but its successful management requires ongoing veterinary treatment and a long-term commitment by the owners (Aptekmann and Schwartz, 2011). The first choices for treatment of diabetes mellitus include oral hypoglycemic drugs, exogenous insulin injection, dietary supplements and exercise, however if the disease is severe fluid and bicarbonate therapy are also recommended (Feldman and Stephen, 2005).

\section{Pancreas and its endocrine hormone production}

Pancreas is a small dual functional gland located in the abdominal cavity near to small intestine, having both exocrine and endocrine functions. The exocrine part secretes digestive enzyme containing pancreatic fluid that help to further break down the carbohydrate, proteins and lipids or fats. Endocrine function of the pancreas is performed by islets of Langerhans. The islets comprise of four type of cells; alpha cell that secrete hormone glucagon, the beta cells which release insulin, delta cells that secrete somatostatin and gamma cells responsible for pancreatic polypeptide ( Aiello and Mays, 2005). Insulin produced by beta cells of pancreas, plays a central role in regulation of carbohydrate, protein and fat metabolism in the body. It causes absorption of glucose from blood by the cells of liver, skeletal muscles and fat tissue. In the liver and skeletal muscles, glucose is stored as glycogen and in adipocytes it is stored as triglycerides (Cunningham, 2002).

\section{Classification of diabetes mellitus}

The classification of diabetes mellitus in dogs and cats has more or less followed the scheme used in human medicine, although the etiopathogenic mechanisms may not be completely identical. Diabetes has been broadly classified into TYPE I and TYPE II based on the degree of beta cell injury (Nelson and Reusch, 2014).

Catchpole et al., (2008) classified two forms of canine DM; insulin deficiency diabetes (IDD) with absolute insulin deficiency and insulin resistance diabetes (IRD) with relative insulin deficiency. $\beta$ cell loss in pancreas associated with uncontrolled hyperglycaemia can lead to the complication of IRD and its progression to secondary IDD. 
Type I diabetes mellitus (insulin dependent diabetes mellitus) is characterized by destruction of $\beta$ cells of the pancreas and complete loss of insulin secretion, manifested by permanent hypoinsulinemia, essentially no increase in endogenous serum insulin levels. This type occurs most commonly in dogs, to certain extent also in cats. In this type of diabetes loss of $\beta$ cells is irreversible so chances of developing diabetic ketoacidosis is higher as compared to type II diabetes (Feldman and Stephen, 2005). The etiology of type I diabetes in dogs is multifactorial. Genetic predispositions have been suggested by familial associations, pedigree analysis of Keeshonds, and genomic studies aimed at identification of susceptibility (Guptill et al., 2003). A number of genes associated with diabetes susceptibility in humans have been linked with high risk of diabetes in dogs. Genes associated with diabetes in dogs are major histocompatibility complex class II genes [dog leukocyte antigen (DLA)], with similar haplotypes and genotypes identified in the breeds most susceptible for diabetes (Catchpole et al., 2013).

Type II (non-insulin dependent diabetes mellitus) is less common in dogs and more common in cats. Principle pathological alteration in type II diabetes is impaired insulin secretion by $\beta$ cells, insulin resistance in insulin responsive tissue and acceleration of hepatic glucose. The ability of beta cells to secrete insulin is present, however, the secretory response to stimulation is delayed and the amount of insulin secretion in abnormal (Feldman and Stephen, 2005).

In addition to the two major types of diabetes, some other forms exist that account for a small proportion of total diabetic case. Gestational diabetes mellitus (GDM) has been documented in dogs during pregnancy and diestrous, though no report in cats is available (ADA, 2013). Previous reports suggest that
GDM affects middle aged bitches in the latter half of gestation with a breed disposition in Nordic Spitz. It has been reported that GDM resolves within days to weeks after whelping. GDM is most often attributed to reduced insulin sensitivity in healthy bitches after 1 month of gestation and increased levels of progesterone (Fall et al., 2008). Overt diabetes during diestrus in bitches may be due to higher levels of progesterone causing glucose intolerance (Kim et al., 2012). Juvenile diabetes, a form of insulin dependent diabetes mellitus has also been reported in canines with particular prevalence in golden retrievers, German shepherd and keeshonds (Kang et al., 2008).

\section{Clinical manifestations}

The most common clinical manifestations of diabetes mellitus are polydipsia, polyuria, polyphagia, weight loss and glucosuria. Untreated or improperly managed diabetes, may lead to change in the acidity of blood (diabetic ketoacidosis) with dehydration, vomiting, depression, coma and ultimately death (Feldman and Nelson, 2004). Other clinical signs can be weight loss, bilateral cataracts and weakness (Bruyette, 2013). Canine diabetes mellitus is a disorder with several pathological mechanisms and complication of abnormal metabolism complications. Poluuria and polydipsia occurs due to abnormal carbohydrate metabolism and responsible for cataract formation in diabetic dogs. Hyperlipidemia, ketone production and hepatic changes are primarily due to altered fat metabolism. Cataracts start to develop within 5-6 months course of diabetes and approximately $80 \%$ of the diabetic dogs will have significant cataract formation by 16 months of disease course (Kumar et al., 2014). Diabetic animals are more prone to bacterial and fungal infections and are likely to develop chronic or recurrent infections such as cystitis, prostatitis, 
bronchopneumonia and dermatitis. This increased susceptibility to infection may be related to impaired chemotactic, phagocytic and antimicrobial activity due to decreased neutrophil function (Bruyette, 2013).

Two serious and potentially life-threatening complications of diabetes mellitus are ketoacidosis and hyperglycemic hyperosmolar non-ketotic syndrome. These forms of diabetes are often precipitated by concurrent diseases like pyelonephritis, pyometra, hyperadrenocorticism, pancreatitis, renal and heart failure. Ketosis in diabetic dogs has been attributed to the glucagon-insulin ratio (Durocher et al., 2008). In pregnant bitches, there is suppressed transport of intracellular glucose, thus causing hyperglycemia along with decreased production of glucose in response to hypoglycemic state, so a slight food deprivation in pregnant bitches may cause hypoglycemia and ketonemia (Johnson, 2008).

\section{Diagnosis}

Conventionally diagnosis of canine diabetes mellitus is based on persistent fasting hyperglycemia and glucosuria. Blood glucose concentration for evaluation of diabetes mellitus has a drawback that it fluctuates with factors like time of the day and stress, etc. (Kumar et al., 2014). The normal fasting value for blood glucose in dogs and cats is $75-120 \mathrm{mg} / \mathrm{dL}$ and renal threshold for glucose is $180 \mathrm{mg} / \mathrm{dl}$ (Bruyette, 2013). $\beta$-cell specific antibodies and $\mathrm{C}$-peptide concentration are important parameters for diagnosis of immune-mediated diabetes mellitus in dogs. In human patients measurement of C-peptide provides a sensitive and clinically valid assessment of $\beta$-cell function (Palmer et al., 2004). Diabetic dogs have more viscous urine than normal and often have a sweet odor and high specific gravity with increase in blood glucose levels. Excess amount of glucose is excreted through urine which is beyond kidney's renal threshold capacity (Wubie and Getaneh, 2015).

Various factors like stress, medication or other diseases can affect the plasma glucose levels and thus interfere with the diagnosis and management of diabetes mellitus (Marca et al., 2000). As an alternate to this, serum fructosamine and glycated hemoglobin $(\mathrm{GHb})$ measurements are increasingly used to complement blood glucose concentration in the diagnosis and treatment response monitoring of canine diabetes mellitus (Kumar et al., 2014). Glycated hemoglobin and serum fructosamine are both products of a nonenzymatic and irreversible process. Glycated haemoglobinis directly related to serum glucose concentration and erythrocyte lifespan. Serum fructosamine is formed through reactions between glucose and serum proteins. Fructosamine concentration directly depends on the blood protein concentrations and their composition (Loste and Marca, 2001). Both fructosamine and glycated haemoglobin are said to be equally efficacious, However, fructosamine has advantage over $\mathrm{GHb}$ based on simplicity and cost benefits of estimation methods. A single measurement of fructosamine reflects glycemic control over the past 2-3 weeks, whereas $\mathrm{GHb}$ can reflect the same for the past 6-8 weeks (Marca et al., 2000). Serum glycated albumin (GA) has been suggested as an alternative to fructosamine estimation and is reported to be a useful diagnostic indicator to monitor glycemic control in diabetic dogs. In diabetic dogs, serum glycated albumin concentrations are reported to be $>11.9 \%$ (Sako et al., 2008). A strong correlation between fructosamine and glycated albumin has been established and the relative stability of glycated albumin percentage establishes its usefulness as a diagnostic indicator in monitoring of glycemic control in diabetic dogs (Sako et al., 2009). 


\section{Treatment}

Diabetes mellitus is complex disease to treat as it is a multi-organ affecting problem. The primary goal of diabetes treatment is maintenance of patient's blood glucose levels as close to normal as possible i.e. $100 \mathrm{mg} / \mathrm{dL}$. This can be achieved by proper insulin administration, diet, regular exercise regimes, oral hypoglycemic drugs and avoidance or control of concurrent illness that may complicate the animal's diabetic state (Rheal et al., 2003).

The use of oral hypoglycemic agents (glipizide) has been evaluated in diabetic cats and to lesser extent in dogs (Bruyette, 2013). The major groups of oral hypoglycemic agents used in veterinary practice worldwide are Sulfonylureas, Bigunide and Thiazolidinedione (Wubie and Getaneh, 2015).

Insulin therapy is the backbone of the management protocol in a diabetic patient with a goal of stabilizing blood glucose levels at or near normal without much complication (Feldman and Stephen, 2005). Various type of insulin are used for treatment of diabetes mellitus in dogs, these are: short acting insulin (regular or crystalline), intermediate acting (NPH and Lente) and long acting insulin (Ultralente and PZI) (Wubie and Getaneh, 2015). However, only two insulin products are presently approved by Food and Drug Administration (FDA) for use in diabetic dogs, these are porcine lente (Monroe et al., 2005) and protamine zinc (Rucinsky et $a l ., 2010)$. In general large breed dogs require only a single dose of insulin per day whereas small breed dogs may require frequents doses of insulin like twice a day. The action of insulin is variable in each individual therefore a large dog may require two shots of insulin daily. Due to the individual variation in the insulin requirement, an insulin glucose response curve should be performed before deciding the dose and frequency of insulin administration and the feeding time of animal (Feldman and Nelson, 2004). Rucinsky et al., (2010) in the guidelines on management of diabetes in dogs and cats recommended a starting dose of $0.25 \mathrm{U} / \mathrm{kg}$, twice a day along with feeding of equally sized meals twice a day at the time of insulin injection. The aim of dietary therapy is to correct obesity and maintain consistency in the timing and caloric contents and plan a diet that causes minimum blood glucose fluctuations post feeding (Ettinger and Feldman, 2005). Diets high in fiber are capable of promoting weight loss, causes slow absorption of glucose from intestine and reduction in postprandial blood glucose fluctuation. Exercise plays an important role in the management of diabetes by helping in weight loss and by eliminating insulin resistance induced by obesity (Feldman and Nelson, 2005).

Alternate therapies for canine diabetes mellitus have been studied, but only a few have reached its clinical application. Use of encapsulated islet in diabetes therapy, current progress and critical issues requiring solution have been evaluated (Scharp and Marchetti, 2014). Gene therapy based on viral vector, using adeno-associated virus encoding for glucokinase and insulin in canine diabetes had consistent desirable effects consistently for four consecutive years of study (Callejas et al., 2013). Success has been recorded in similar studies undertaken in mouse's model (Mas et al., 2006).

\section{References}

Aiello, S.E., and Mays, A. 2005. Endocrine disorder. Merck Veterinary manual 9th ed., Inc. Merck and CO. USA. Pp: 438441.

American Diabetes Association. 2013. Standards of medical care in diabetes - 
2013. Diabetes Care. 36(1): 11-66.

Aptekmann, K. P., and Schwartz, D. S. 2011. A survey of owner attitudes and experiences in managing diabetic dogs. The Veterinary Journal. 190: 122-124.

Audrey, K. C. 2012.Monitoring Methods for Dogs and Cats with Diabetes Mellitus. Journal of Diabetes Science and Technology. 6(3): 491-495.

Bruyette, D. 2013. The Pancreas. The Merck Veterinary Manual. 8th ed. Merck Sharp \&Dohme Corp., USA.

Callejas, D., Mann, C.J., Ayuso, E., Lage, R., Grifoll, I., Roca, C., Andaluz, A., Ruizde Gopegui, R., Montané, J., Muñoz, S., Ferre, T., Haurigot, V., Zhou, S., Ruberte, J., Mingozzi, F., High, K.A., Garcia, F. and Bosch, F. 2013. Treatment of diabetes and long-term survival after insulin and glucokinase gene therapy. Diabetes. 62(5): 1718-29.

Catchpole, B., Adams, J. P., Holder, A. L., Short, A. D., Ollier, W. E. and Kennedy, L. J. 2013. Genetics of canine diabetes mellitus: are the diabetes susceptibility genes identified in humans involved in breed susceptibility to diabetes mellitus in dogs? Veterinary Journal. 195:139-147.

Catchpole, B., Kennedy, L.J., Davisony, L.J. and Ollier, W.E.R. 2008. Canine diabetes mellitus: From phenotype to genotype. Journal of Small Animal Practice. 49(1): 4-10.

Cunningham, J.G. 2002. Endocrinology. Text book of Veterinary Physiology 3rd ed., Inc. W. B. Saunders. USA. Pp. 324-372.

Durocher, L.L., Hinchcliff, K.W., DiBartola, S.P. and Johnson, S.E. 2008. Acid-base and hormonal abnormalities in dogs with naturally occurring diabetes mellitus. Journal of American Veterinary Medical Association. 232(9): 1310-20.

Ettinger, S.J. and E.C. Feldman, 2005. Diabetes mellitus. Textbook of
Veterinary Internal Medicine. Vol. II, 6 ed. Elsevier, St. Louis MO. Pp. 15771578.

Fall, T., Kreuger, S. J., Juberget, A., Bergström, A. and Hedhammar, A. 2008. Gestational diabetes mellitus in 13 dogs. Journal of Veterinary Internal Medicine., 22(6):1296-1300.

Feldman, E.C. and Nelson, R.W. 2004. Pet Endocrinology and Reproduction. Text book of Small Animal Medicine. 3rd ed., Inc. W. B. Saunders. Philadelphia, USA, Pp. 539-597.

Feldman, E.C. and Stephen J. E. 2005.Endocrine disorders. Text book of Veterinary Internal Medicine.6 ed., Inc. Elsevier. USA, Pp. 1563-1592.

Guptill, L., Glickman, L. and Glickman, N. 2003. Time Trends and Risk Factors for Diabetes Mellitus in Dogs: Analysis of Veterinary Medical Data Base Records (1970-1999). The Veterinary Journal. 165: 240-247.

Johnson, C.A. 2008. Glucose homeostasis during canine pregnancy: Insulin resistance, ketosis, and hypoglycemia. Theriogenology. 70: 1418-23.

Kang, J. H., Ki-Jeong, N. A., In-Pil, M. O., Chang, D. and Yang, M. P. 2008. Juvenile Diabetes Mellitus Accompanied by Exocrine Pancreatic Insufficiency in a Dog. Journal of Veterinary Medical Science. 70(12): 1337-40.

Kim, A.Y., Kang, J. H. and Yang, M. P. 2012. Transient diestrus-related diabetes mellitus in a dog. Journal of Biomedical Research. 13: 265-67.

Kumar, P., Kumari, R.R., Kumar, M., Kumar, S. and Chakrabarti, A. 2014. Current practices and research updates on diabetes mellitus in canine, Veterinary World, 7(11): 952-59.

Loste, A. and Marca, M. C. 2001.Fructosamine and glycated hemoglobin in the assessment of 
glycaemic control in dogs. Veterinary Research. 32: 55-62.

Marca, M.C., Loste, A. and Ramos, J.J. 2000.Effect of acute hyperglycaemia on the serum fructosamine and blood glycated haemoglobin concentrations in canine samples. Veterinary Research Communications, 24(1): 11-16.

Mas, A., Montane, J., Anguela, X.M., Munoz, S., Douar, A.M., Riu, E., Otaegui, P. and Bosch, F. 2006. Reversal of type 1 diabetes by engineering a glucose sensor in skeletal muscle. Diabetes. 55(6): 1546-53.

Monroe, W.E., Laxton, D., Fallin, E.A., Richter, K.P., Santen, D.R., Panciera, D.L., Todd, L.T., Kimberly, A.W., John, R.H., Steve, H., Mark, R.F. and Shinn, J.S. 2005. Efficacy and safety of a purified porcine insulin zinc suspension for managing diabetes mellitus in dogs. Journal of Veterinary Internal Medicine. 19: 675-682.

Nelson, R. W. and Reusch, C. E. 2014. Animal models of disease: classification and etiology of diabetes in dogs and cats. Journal of Endocrinology. 222(3): $1-9$.

Palmer, J.P., Fleming, G.A., Greenbaum, C.J., Herold, K.C., Jansa, L.D., Kolb, H. and Steffes, M.W. 2004. C-Peptide is the appropriate outcome measure for type 1 diabetes clinical trials to preserve $\beta$-cell function report of an ADA workshop. Diabetes, 53(1): 250-64.

Rheal, V., M. Ronald, M. Bright and S.
Swartout, 2003.Endocrine and metabolic system. Hand book of small animal practice 4th ed., Inc. W. B. Saunders. Philadelphia, London, New York, Sydney and Tokyo, pp: 470-476.

Rucinsky, R., Cook, A., Haley, S., Nelson, R., Zoran, D.L. and Poundstone, M. 2010. AAHA diabetes management guidelines for dogs and cats. Journal of American Animal Health Association., 46(3): 21524.

Sako, T. A., Mori, P., Sato, T., Mizutani, H., Takahashi, T., Kiyosawa, Y., Tazaki, H. and Arai, T. 2009. Serum glycated albumin: Potential use as an index of glycemic control in diabetic dogs. Veterinary Research Communication. 33: 473-79.

Sako, T., Mori, A., Lee, P., Takahashi, T., Izawa, T., Karasawa, S., Furuuchi, M., Azakami, D., Mizukoshi, M. Mizutani, H., Kiyosawa, Y. and Arai, T. 2008. Diagnostic significance of serum glycated albumin in diabetic dogs. Journal of Veterinary Diagnostic Investigation. 20(5): 634-38.

Scharp, D.W. and Marchetti, P. 2014. Encapsulated islets for diabetes therapy: History, current progress, and critical issues requiring solution. Advanced Drug Delivery Reviews. 67-68: 35-73.

Wubie, A. and Getaneh, G. 2015. Factors and Management of Diabetes Mellitus in Pets. European Journal of Applied Sciences. 7(5): 241-249.

\section{How to cite this article:}

Shabnam Sidhu and Swaran Singh Randhawa. 2019. A Review on Diagnosis and Management of Diabetes Mellitus in Dogs. Int.J.Curr.Microbiol.App.Sci. 8(06): 10-16. doi: https://doi.org/10.20546/ijcmas.2019.806.002 